\title{
\#MeToo as a Failed Movement of Women Empowerment in Pakistan: A Critical
}

\section{Discourse Analysis}

* Khush Bakht (Corresponding Author)

** Dr. Sadia Irshad

*** Dr. Abdus Samad

\begin{abstract}
The current study aims to understand the narrative of \#MeToo in Pakistan as formulated by Pakistani Twitter users. Although the \#MeToo movement emerged as a movement of women empowerment against the issues of sexual harassment and domestic violence, however today in the $21^{\text {st }}$-century women are still struggling with longstanding abuses and sexual harassment. The current study has explored how in the patriarchal society of Pakistan, the narrative of \#MeToo is not acceptable and manipulated by certain societal forces for personal gain. Similarly, this research has also understood the influence of dominant discourses on the narrative of \#MeToo. Through the use of Van Dijk's (1998), Ideological square, as a theoretical lens, the results of the study argue that the narrative of \#MeToo is badly exploited subjugated by patriarchal notions to manipulate women empowerment in Pakistan. Two domains of the \#MeToo movement have been explored i.e. Sexual harassment and Domestic violence through the current study and the results have revealed that in the patriarchal society of Pakistan domestic violence is given weightage over sexual harassment. Furthermore, Patriarchy has argued that the \#MeToo movement is a movement of fame, to which the proponents of the \#MeToo movement referred as Fame: A Blame Game to the movement. Lastly, the recommendations are offered as well.
\end{abstract}

Keywords: Domestic Violence, Empowerment, Ideological Square, \#MeToo Movement, Patriarchy, Sexual Harassment

\section{Introduction}

The term Me Too, first used by Tarana Burke in 2006 (Ohlheiser, 2017), has gained immense popularity since October 2017 through Twitter. Me Too - a small-scale movement- initiated an international conversation about the problem of sexual harassment and assault faced by women (Rodriguez, 2018), thereby evolving into a global phenomenon. Ohlheiser (2017) opines that the famous Hollywood actress Alyssa Milano was the first person to bring the \#MeToo movement to the limelight and made it public through her tweet on 17th October 2017. In her tweet, she encouraged the victims of sexual harassment to use the \#MeToo to speak openly about their sexual harassment experiences and trauma. It is significant to understand that the literal meaning of \#MeToo is not only restricted to the problem of sexual harassment but also takes into account child molestation and domestic violence cases.

This study attempts to understand the discourse generated by the \#MeToo movement in Pakistani society as propagated by Pakistani Twitter users. Through the use of social media as a data source, we have explored the prevailing perception of \#MeToo in Pakistani society and its implication on our daily life. Although \#MeToo emerged as a movement of women empowerment, however, women today continue to struggle with sexual harassment, domestic violence, and oppression. They are still striving to be heard and have their issues acknowledged both in professional and personal life. Social Media has proven to be a significant platform to bring international attention to women's rights (Vardhan, 2017). Therefore, through the analysis of tweets, we have explored certain social, political, cultural, and religious factors involved in the failure of the \#MeToo movement in Pakistan. Based on the assumptions of the study the following section attempts to identify and explain the problem of

\footnotetext{
* Department of English, Air University, Islamabad Email: kbakht66@ gmail.com

** Department of English, Air University, Islamabad Email: Sadiyairshad@ gmail.com

*** Department of English, Kohat University of Science \& Technology, Kohat Email: dr.samad@kust.edu.pk
} 
\#MeToo in Pakistan. The current study explores whether the use of social media is basically addressing the situation in its true sense or is it just strengthening the perpetrator by giving it more strength.

\section{Statement of the Problem}

The Pakistan of the $21^{\text {st }}$ century still finds itself enmeshed in patriarchy, despite women making a significant contribution in every field (Chauhan, 2014), they are still struggling to combat different types of harassment in their daily life. It is due to the pervasive patriarchy that even to date women holding prestigious posts at national and international level face harassment in one way or another which not only affects their personal life but it has also shaken their self-esteem and confidence of being an independent woman. Based on the problem statement the following section will discuss two major research questions.

\section{Research Questions}

Q1: What is the narrative of the \#MeToo movement generated by the Pakistani Twitter Users?

Q2: How does the dominant discourse of Patriarchy is influencing the narrative of women empowerment?

The current study is significant not only in social and ideological perspectives but in the academic standings as well. In the domain of social standings, the current study unveils the moral corruption of patriarchy in Pakistan. This research also paves the path to explore gender hierarchies in Pakistan. Similarly, it also presents the ideological differences and how the ideological narrative of patriarchy has subjugated the narrative of women empowerment or \#MeToo. Notwithstanding the due coverage of the literature, we argue that the concept of \#MeToo is yet to be explored and highlighted in the social premises of our country i.e. Pakistan. While going through the number of works we conclude that the \#MeToo movement was originated by educated middle-class women to propagate not only their problems of sexual abuse and domestic violence but also to provide a forum to the women of other classes as well. However, even today the women working in the different sectors of society still face harassment in one way or another. Similarly, being a very burning topic, especially in the patriarchal society of Pakistan, a huge amount of research needs to be taken place in this field and we hope that our research will add to the already existing corpus of knowledge.

\section{Literature Review}

With the emergence of \#MeToo in Pakistan, women have started to speak against the prevalent harassment on social media (Mehmood, 2018), yet it is far from being heard. The current study assumes that one of the significant causes of the failure of \#MeToo is the deep-rooted patriarchy. Similarly, it is significant to assume that the narrative of \#MeToo in Eastern society is not contextualized; that is to say that the prevailing narrative is not acceptable in the deeply rooted patriarchal society, thus leading to its failure as a movement of women empowerment. The purpose of the current study is to investigate the narrative of \#MeToo in Pakistan and to explore how the cultural implications of our society are influencing this narrative and investigate the narrative of \#MeToo propagated by Pakistani Twitter users.

In the 21 st century where independent women are a great source of inspiration for women needing empowerment, the theoretical assumptions of women empowerment are far from the reality prevailing in Pakistani society (Rasul, 2014). In recent times, where our lives are deeply shaped by social media, we can see the impact of \#MeToo on the film industry. It is due to this reason that \#MeToo gained popularity through the tweets of famous Hollywood filmmaker and director Alyssa Milano. Sayej (2017) quoted the tweet of Milano in which she urged other women who were ever abused or harassed sexually in life to use \#MeToo as a reply to her tweet. While giving an interview to one of the famous newspapers Milano (2017) stated that it is alarming to see the number of sexually harassed victims not only in the film industry but in the other industries as well. While celebrating the success of the \#MeToo movement she argued that it was surprisingly beautiful to see the success of this movement, however, it was not intended (Milano, 2017). However, this campaign is used as a tool of violence against women through social media and it acts as a regularity mechanism for the feelings and emotions of sexually abused women.

Gash and Harding (2018) posit that to give weightage to the voice of the victims of sexual harassment, there must be a legal procedure since the unprivileged do not have direct access to social media. Legal options remain largely inviable for most victims of sexual assault (Gash \& Harding, 2018). Furthermore, it is asserted that movements like \#MeToo help in raising the conscience of legal 
prosecutors. In addition to this, Gash and Harding (2018) consider \#MeToo as a consciousness-raising movement, "... legality in the context of consciousness-raising potentially operates in ways that are counterproductive, encouraging victims of sexual violence to stay silent and to second-guess their experiences, perceptions and reactions (p. 21)".

In the field of Journalism and media \#MeToo movement has suffered a lot. Evan (2018) argued that journalists and newspapers, report writers divided this movement based on racial differences. Evan (2018) asserted that "by framing sexual assault as an issue affecting white people more than people of color, The New York Times is exhibiting white feminism (Evan, 2018, p. 14)".

Moreover, Franiuk (2008) stated that there is always a proper code of journalism for covering the victims of sexual assault. Despite this guideline, previous researches indicate that journalists do not follow the code when covering sexual assault (Franiuk, 2008). Burke (2019) lamented about the discrepancies in which the \#MeToo movement has fallen i.e. racial discrimination. She further added that, "The women of color, trans women, and queer people — our stories get pushed aside and our pain is never prioritized. Their stories go untold" (Burke, 2019, Personal Communication).

In Pakistan, \#MeToo gained popularity through electronic and social media, especially when Meesha Shafi accused Ali Zafar of sexually harassing her. However, Mahfooz (2019) believes that in Pakistan, female suffers in a taboo-stricken society. In a traditionally strict society like Pakistan, the \#MeToo movement is evolving with time and it may take several years to break down the concept of the taboo associated with it. Furthermore, Khan (2019) stated that when it comes to sexual harassment, Pakistani women suffer in silence. A certain key change in the norms and traditions of our society can become a key factor in changing the narrative of \#MeToo.

Within the context of our social and cultural milieu, it is observed that women who are too vocal about their rights are labeled as 'troublemakers'. They are viewed as slogan mongers and no heed is paid to their suffering and struggles. Such women are labeled as 'Feminists' pejoratively and thus are ignored for whatever they ask regarding their rights. Khan (2019) believes that it is due to this reason that in Pakistani society sexual harassment has become a norm and those who speak against it are labeled as 'troublemakers'. Wasif (2018) gave an alarming report of the increase in the number of sexual harassment reports provided by FOSPAH (Federal Ombudsperson for Protecting against Harassment). According to that report, a total number of 244 cases were filed from July 2017 till June 2018, out of which most of these cases were filed from women. This suggests that women in the government sector feel unsafe equally as that of the women working in the private sectors.

\section{Research Methodology}

The current research falls in the research paradigm of interpretivism, i.e. the research is based upon the interpretation and developed an understanding of a researcher. Through the use of a qualitative research paradigm, we have explored the narrative of the \#MeToo movement in the Pakistani context. We have used tweets as our research data source, and through purposive sampling, tweets were generated by using the following hashtags.

\begin{tabular}{ll}
\hline \#MeToo & \#MeToo Pakistan \\
\hline \#Sexual Harassment & \#Domestic violence \\
\#Ukhano & \#Mohsin Abbas Haider \\
\#Womencard \#HimToo & \#shame on you
\end{tabular}

Table No. 1.

The theoretical framework that we have incorporated in the current research is the concept of Ideological Square presented by Van Dijk (1998). Through the use of in-group and out-group, we have elaborated the ideological tussle going between patriarchy and women empowerment.

\section{Ideological Square}

Van Dijk, a famous linguist and discourse analyst (Ahmadvand, 2011) argues that although discourse and society are interdependent yet there is another element that plays a significant role in developing the discourse of society. In his book, Van Dijk (1998) gave a detailed example of how ideologies constructed through cognition in society help in creating binaries not only in the discourses but in the society as well. Social conflicts among different groups are always excelled by personal interests. Such conflicts occur often between dominance encountered by resistance, thus together representing a 
social struggle. Based on the ideological presentation of discourse Van Dijk proposed Ideological Square or conceptual square. He proposed four major tenets of Ideological Square. They are:

- $\quad$ Emphasize a positive image about $U s$.

- $\quad$ Deemphasize negative image about $U s$.

- $\quad$ Deemphasize negative image about Them.

- $\quad$ Emphasize positive image about Them.

These four significant features of Ideological Square (1998) play a significant role in positive-self representation and negative-others representation. This positive-self representation and negative-others representation is the fundamental backbone of ideologies. Van Dijk argues that such marginalization of others is a cause of polarization in society. Most of the time dominant discourse plays an efficient role in marginalizing others' viewpoints. Van Dijk (1998) argued that "ideologies are representation of who we are, what we stand for, and what our relationships are with other groups" (p. 67).

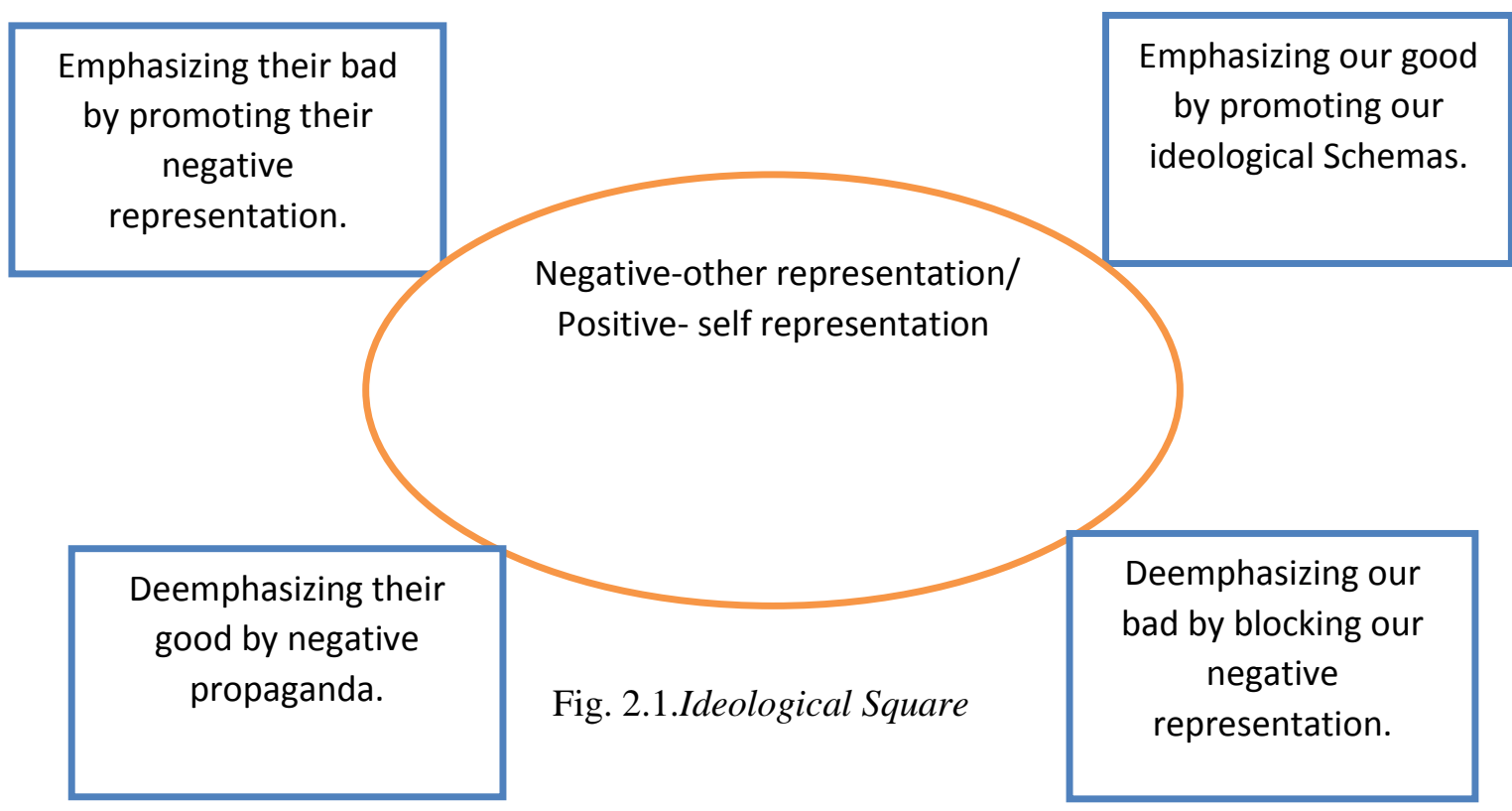

It is significant to understand that the \#MeToo movement emerged as a movement of women empowerment against sexual harassment, and domestic violence. In Pakistani society, where women, for most of the time are confined to the premises of the home, the narrative of \#MeToo is not successful in its real sense. Through the use of tweets, we have elaborated on how the constructed ideology against \#MeToo is pushing aside its real narrative of women empowerment and how through the use of social media people are Othering the real narrative of \#MeToo. The voices of women, for most of the time, do not receive any legal implications and the voices remain unheard in the presence of the dominant discourse of patriarchy.

In the context of our study, we have selected two domains of \#MeToo discourse i.e. Ukhano; a famous you tuber who is accused of online sexual harassment, Mohsin Abbas Haider; a famous T.V. actor who is accused of domestic violence. As the discourses of both of the cases were exposed to Twitter therefore the discourses, formed, can be divided into both in-group and out-group. For being public celebrities both of them have fans and haters thus forming both the above-mentioned group. The collected data suggest that the dominant discourse developed in the current situation is deemphasizing the importance of the \#MeToo movement which is based on women empowerment. Through thematic analysis via the Ideological Square lens, we have explored how the in the group i.e. the dominant discourse is deemphasizing the discourse of outgroup.

\section{Data Analysis}

\section{Patriarchy: Emphasizing Our Good/ Emphasizing Their Bad}

The users of social media, especially the tweeps have developed a strong narrative of patriarchy. Instead of finding a solution to the problem of sexual harassment and domestic violence, the patriarchal narrative has tried to emphasize they are good. According to the narrative of us, the 
\#MeToo movement has lost its credibility not because of the increase in the number of sexual harassment and domestic violence issues but because of its manipulative use by women themselves. The narrative of patriarchy as propagated by tweeps also suggests that women are more obsessed with fame and money than their empowerment. For this purpose, women instead of working hard on their own, try different ways to manipulate influential men to get their stardom. For patriarchy the narrative of them i.e. \#MeToo is nothing more than

- A western movement of women empowerment that cannot cope with Pakistani society.

- Similarly, it deals mainly with the defamation of men rather than the empowerment of women in Pakistan.

- A movement of revenge based on biases towards men.

Several themes have emerged from collected data and are discussed below to portray the narrative of patriarchy \#MeToo Pakistani tweets. This narrative has tried to deemphasize the positive cause of the \#MeToo movement and emphasize the negative agenda of \#MeToo and labels it as a movement of manipulation. The following are the major themes that emerged in favor of patriarchy. Similarly, through the use of these themes patriarchy has tried to deemphasize the good of \#MeToo and emphasized their good.

Women Card: \#HimToo

It is the most frequent theme that emerged in the narrative of patriarchy. Hegemonic patriarchy has tried to manipulate the narrative of \#MeToo by stating that the \#MeToo movement is used against men instead of empowering women. They labeled such manipulation as a women's card.

In this regard one of the tweeps UK2, MAH2 accused women of using women's cards. The user asserts that:

"@itsmeeshashafi played women's card on @Alizafarsays and got massive publicity.

Then \#Ukhano then \#MohsinAbbasHaider and now @ImamUlHaq12.Do something

else to gain fame. Boys only have career nothing else, stop ruining society \#MeToo.”

This tweet gave a reference to the previous issue of MeeshaShafi discussed earlier. UK2 urges that females use women's cards to seek attention and fame. In the flow of seeking public attention, women are not aware of the harm they cause to men in terms of their careers. Another user UK3, MAH3 argues in the same context. The user asserts that:

"Stopppp! Stop! Using women card..hidingur replies and highlighting other's and giving it name of sexual harassment. \#MeToo, \#ukhano."

It can also be argued that men who offer such claims are defending themselves against the backlash they receive. By time and again using the phrase of women's card the tweeps are trying to safeguard their notions of patriarchy thus defaming the \#MeToo movement by deemphasizing the bad perspective of patriarchy and deemphasizing the good of the \#MeToo movement. However, tweeps are, for most of the time, of the view that women must not ruin the careers of boys just to get social media fame. In the same context another user UK4, MAH4 states that:

"I have always seen famous stars affected by the \#MeToo movement. \#alizafar, \#ukhano, \#imamulhaq. It's just to defame famous men. Nothing else. If u $r$ sincere with this movement why no girl come up with blame on ordinary man?"

This tweet also suggests that women are more concerned with fame and money and it is due to this schema of money, luxury, and fame that women try to associate themselves with the men having riches and money. The user believes that women must not use the fame of other men to defame them and to gain popularity for themselves. It also describes the hypocrisy displayed by women who accuse men of fame and money. They never accuse men with low social status thus manipulating the movement itself. In the same context another tweep UK5, MAH5 argued:

\#MeToo movement is all about enjoying with male celebrities first and then defame them later while playing victim/women card. \#Ukhano \#MohsinAbbasHaider."

Likewise, another tweep UK6 tried to expose the use of women card and stated:

"\#Ukhano has tried to clear up the matter for us. We are with you, expose those girls who have been enjoying. It's enough for you to be a man. These girls want fame give them shame its \#mentoo instead of fake \#MeToo."

The above-stated tweet gives an insight into another patriarchal notion that is absurd and unethical According to the tweep, in a patriarchal society, if a man wants to prove himself innocent, 
his biological gender of being male itself is enough to prove him right. In Pakistan, hegemonic patriarchy has spread its tentacles so deep that it doesn't bother itself with the accusation of sexual harassment and domestic violence. Such hegemonic patriarchy tries to emphasize its good by shadowing it in gender discrimination and deemphasizes the good of the \#MeToo movement by changing the movement into \#MenToo. In addition to this, another tweep also defended the pattern of hegemonic patriarchy. The tweep UK7 stated:

"If somebody makes a pass at girls does that make them a rapist? Are you out of your mind??? So what if he messages a girl and tries to flirt??? Isn't everyone saying when they don't respond he stops? Girls do the same thing, man. It's not a big deal. \#Ukhano."

This tweet gives an insight into the hypocrisy of patriarchy. The said tweep argued that there is no problem if a man texts a girl and tries to flirt with her. Instead of justifying the said viewpoint, the said tweep tries to justify a man's flirting with a woman's reply in response. Foregrounds, Van Dijk's model of Ideological Square we argue that the narrative of patriarchy tries to present the negative image of \#MeToo or them by directing negative propaganda towards the narrative of \#MeToo. One thing that took our attention in this tweet is about normalizing the concept of open flirting in Pakistan. As mentioned, the tweep argues that, "So what if he messages girl and tries to flirt??? Isn't everyone saying when they don't respond he stops? Girls do the same thing, man. It's not a big deal." In this whole statement, the tweep has not shown any concern about online flirting of boys with the girl. Instead, tweep justified the viewpoint by comparing it with girls thus normalizing the concept of open online flirting which is not very much welcomed and appreciated in Pakistan. In the same context of fame and materialistic gains another tweep UK8 stated:

"Some women like to be asked out no? Keeping religion aside, there is nothing wrong

in asking for consent if it does not result in imposing one's self on the other or making her feel terrified. And \#Ukhano didn't do anything of this sort as long as I have seen posts against him."

This tweet also shades the patriarchal notion of defending men instead of accepting the truth. According to the said tweep, asking girls for consent in flirting is justified for the fact that it must not be merged with religion. The tweep has also tried to make the concept of flirting a commonality by referring to it as an act of consensual flirting rather than imposing it on the opposite gender. One of the other tweeps stated:

"They are first gold diggers after getting nothing they play women's card and then became a part of \#MeToo. \#Ukhano."

This tweet has also tried to deemphasize the narrative of them i.e. \#MeToo by calling it a movement of gold diggers and by considering it as a movement of women's cards as well. Instead of being ashamed of sexually harassing women the patriarchy defends the accusers shamelessly thus enlarging the gap between the \#MeToo movement in Pakistan and the prevailing patriarchal notions. It also gives an insight into the perception of tweeps about the \#MeToo movement. The tweet suggests that in Pakistan, the \#MeToo movement is believed to be used by women who are gold diggers in their nature. Similarly, another tweep UK9 argued:

"\#Ukhano is a victim of wrongly used woman card. Women first gain favors then become a part of \#MeToo. If \#YouToo are part of flirting and sexting, then stop crying and be a victim later."

In the above tweet, we can see that how tweeps are explicitly defending Ukano for his sexual harassment. Instead, they try to consider women as a source of gaining fame thus manipulating \#MeToo and its narrative of women empowerment. In the same context, another tweep UK10 stated:

"Accuse anyone, disgrace him, humiliate him, ruin his career, gain sympathy, gain some fame, gain support from confused feminists, and voila!! That's what \#MeToo about. \#ukhano \#womencard."

This tweet has deemphasized the good of \#MeToo by calling it a movement of confused feminists. According to the tweet women in the propagation of the \#MeToo movement follow a certain pattern. First women try to accuse others by providing false allegations which in turn helps them to gain social media fame. Their fame is not only limited to social media fame but they also gain the sympathy for feminists. Such tweets give an insight into a limited pattern of \#MeToo, which 
according to patriarchy is, followed by women. Another tweep elaborated on his point of view in the same way. The tweep UK11 asserted:

"Their game: have fun with celebrities. Enjoy, become known. Full consent. Nothing

forced. And once things start going outside the plan, or you are done and wanna switch. Leak the chats and cry. \#MeToo."

Again the tweep has tried to accuse women by providing an explicit view and pattern followed by them and become a part of the \#MeToo movement. Likewise, another tweep UK12 stated:

"I don't know why girls play \#MeToo card even when they are also at fault. Why they are eager to talk to famous personalities, and if something bad happens then they blame them for that. Why they act like hypocrites. \#ukhano."

The above-mentioned tweet has tried to question the hypocrisy of women who become a part of the blame game after they talk to famous personalities. The tweep argued that in some cases men are not at fault but rather they become a part of the conversation with men, thus equally become a part of an ongoing conversation.

Likewise, another tweep UK14 stated:

"We nothing to judge to bash to cancel anyone just one biased tweet based on screenshot that can easily be edited. Hold on guys just to wait for the other side story.

It's easy to accuse anyone in the age of social media. Maybe it's just a \#Womencard \#Ukhano."

The above-mentioned tweet has also tried to troll the victims of sexual harassment by calling them out for using women's cards. The said tweet stated that we must listen to both sides of the stories. Instead of believing the victims we should listen to the story of the accused and should ensure that women must not use victim cards to gain sympathy from others.

\section{Legal Action}

Another prominent theme that emerged from the collected data in the narrative of patriarchy is legal actions. For, most of the tweeps argue that blaming men for personal gains is the agenda of the \#MeToo movement and it should be exposed. For, if men harass women then the allegations should be proved in court instead of venting them around on social media. While talking about the legal implication one of the users UK15, MAH7 says that:

"\#MeToo movement exposed. ImamulHaq and \#ukhano fake allegations are absolute scums of society. Courts must take them to task. Anyone can be destroyed in minutes with fake allegations in the social media era."

The content of this tweet is again blaming societal norms and tradition for producing scum and issues of the blame game in society. UK8 also argued about the genuine status of \#MeToo by referring to it as the '\#MeToo movement exposed'. Here we can argue that in certain instances people have developed a notion that the \#MeToo movement has lost its real sense and its real essence is lost somewhere between patriarchy and feminism. UK15 further urges the lawmakers to take necessary actions against those who are manipulating a global movement for personal gains. Another tweep UK42 argued:

"Dear accusers, if you have proper screenshots, file an official complaint of harassment, then your case will be heard and the conversation will be checked and he will be charged guilty. Simple. Stop this friend of a friend of a friend of a friend who said he's creepy. \#Ukhano"

It must be kept in mind that when Umar Khan aka Ukhano was accused of sexual harassment, a common trend was started by accusers in which they used to substantiate their argument by referring to the case of their friends instead of providing strong shreds of evidence for sexual harassment against Ukhano. The above-mentioned tweet is one of the examples in the same regard and the tweep argues that it is significant to take proper legal action when it comes to such a delicate issue of sexual harassment because it not only causes a problem for the accused but it can create genuine problems for the accusers as well. Within the themes of persuasion of \#MeToo through law several sub-themes emerged and these themes are further aiding to the importance of law in society especially when it comes to the issues of sexual harassment and domestic violence in society. These sub-themes are discussed below. 
- $\quad$ Law: A Threatening Tool for Victims

On one hand, patriarchy has asked the importance of law in the context of the \#MeToo movement, and on the contrary, few of them have tried to use legal implication as a source of threatening the proponents of \#MeToo. In this context, one of the tweeps UK16 stated:

"In the case of \#Ukhano, those who are posting insta stories, tweets, and memes against him, the screenshots have been taken and provided to the FIA. Similarly, a complaint has also been lodged against them. The celebrities who have posted against ukhano should stop becoming social media champions. \#MeToo"

The said tweet gives a glimpse of patriarchal notions and argues that the law is going to decide the real culprit in the whole scenario of \#MeToo. This tweet also suggests the importance of law and the Federal Investigation Agency in the issues of sexual harassment and domestic violence. The tweet also gives an insight into the implication of law in society and how patriarchy can use the law as a source to threatening the victims of \#MeToo.

\section{- $\quad$ Social Media: A Witch Hunt}

Furthermore, according to the narrative of patriarchy, social media acts as a witch hunt that brings harm and defames the people in society. Therefore, it is important to take the matter into court for clear results, justice, and resolution. While targeting the narrative of \#MeToo, tweeps tried to deemphasize the good of \#MeToo by calling it a movement of a witch hunt. In the same context, one of the tweeps UK17 stated:

"Where do you draw the line for social media witch hunt? Ali Zafar was accused and maligned and then it turned out to be otherwise in the court. Therefore in Ukhano's case, proper proofs should be provided. \#Ukhano."

In this tweet, while talking about the legal action in societal scum the tweep argued that \#MeToo is all about social media fame and then the tweep related the argument with the case of Ali Zafar. The tweep stated that Ali Zafar was proved innocent in the court therefore, those who blame Ukhano for sexual harassment should provide proper proofs in court instead of defaming him on social media. To stop this witch hunt one of the tweeps UK18 stated:

"All the false accusers must face defamation charges, it's time we stop this witch hunt

and defame people to ruin their lives and careers! \#MeToo \#Ukhano."

In the said tweet we can see how the patriarchal strand in our society has tried to accuse the accusers by asking the law enforcement authorities to charge them for creating havoc against Ukhano and other social media influencers. Similarly, the tweep further argues that the witch hunt of social media should be stopped immediately because it is a source of defaming others and ruining their careers.

\section{\#MeToo: A Fame Game}

One of the themes from the collected data is that \#MeToo is perceived as a movement of a blame game. According to the dominant discourse of Us. i.e. patriarchy, the narrative of \#MeToo acts as a blame game for men. Through positive-self representation and negative-other representation, patriarchy argues that the \#MeToo movement is limited to the career downfall of men in our society. For, most of the women accuse men not only to gain fame but also to defame men and bring their careers down. In this context, one of the tweeps UK19 argued:

"I cannot believe how sick-minded we all are that we love to ruin someone's entire life's hard work by maligning their character. Just because we cannot get fame like him so we start pulling legs and speaking trash about his character. \#Ukhano."

In this tweet the tweep has tried to lament the existing dilemma of our society, i.e. to gain fame by pulling other legs and not by working hard. Furthermore, the tweep argued that as a nation our mentality is pigeonholed in creating problems for others instead of cherishing them for their success. Similarly, another tweep UK20 stated:

"Amazed on how in a matter of seconds a career can end. More power to the civil society for standing up against people who think they can do anything they want because of their "fame" \#ukhanoexposed \#ukhano \#Pakistan."

Here, again the narrative of patriarchy has deemphasized the narrative of \#MeToo by labeling it as a movement of fame, which only focuses on the gain of social status.

Likewise, another tweep UK21 asserted: 
"Seeing someone tweets about Ukhano! First of all, where is the proof? How could you ruin someone's life's hard work by unconfirmed speculations? So disappointing. If you have any concrete proof then share \#Ukhano."

In addition to the use of societal gains, the \#MeToo movement accuses others not based on any substantial grounds but based on some petty screenshots which can be made with any app these days. The said tweep argued that the \#MeToo movement in Pakistan is quite a disappointing one as it does not provide any significant proof.

In addition to this, another tweep UK23 argued:

"A lot of people accusing Ukhano of harassment simply on the basis that he added them on Instagram. I simply cannot understand these people. Please show proof before ruining someone's life."

The content of the above-mentioned tweep also states that instead of providing any significant proof \#MeToo is all about defaming others for financial gains.

Furthermore, another tweep UK22 stated:

"People now believe in blind game. Another person is now accused of sexual assault and without any research, people start defaming him. Sigh. Stepping over someone's lifetime hard work shouldn't be this easy. \#letslistentobothsidesofthestory \#Ukhano."

Subsequently, another tweep UK24 said:

"All those people who are bashing him without any evidence are morons. Just because an unknown girl posts an alleged picture of him wanting to follow her doesn't equate to rape. Pakistanis grow up. Stop getting manipulated all the time. \#Ukhano."

In like manner, another tweep stated UK25 ironically:

"Just fact of liberalism, it takes ages to develop career and it takes second to destroy the whole career \#Ukhano."

All the above-mentioned tweets developed a discourse of defaming men and negating the proofs provided against Ukhano. Furthermore, it is argued that the narrative of patriarchy is directly influencing the narrative of \#MeToo by not accepting the provided screenshots as proof against Ukhano. Similarly, instead of believing the stories of a victim, the developed discourse presents that the \#MeToo narrative is all about manipulating famous men for the personal benefits of women. One of the significant aspects of the tweets mentioned above is about the standing of the \#MeToo movement in Pakistani society. According to the tweep \#MeToo movement in Pakistan is related to so call harassment is not based on any substantial ground but fame and money.

\section{\#MeToo: Emphasizing Our Good/ Emphasizing their Bad}

On the contrary, to the narrative of the patriarchy, a significant amount of discourse was developed in the favor of \#MeToo movement. Likewise, the narrative of patriarchy, the discourse of the \#MeToo moment in favor of women empowerment is also based on certain themes. The tweets, propagated, have supported \#MeToo in the context of law, social awareness, the norms of patriarchy, by discussing the social taboos and by dismantling the definition of women empowerment through patriarchal traditions. The following emerged themes play a vital role in understanding women empowerment and the positive discourse of \#MeToo in Pakistan. The emerged themes also depict the awareness created by the \#MeToo movement in the masses. Here, it is significant to understand that the emerged themes in both the narratives are almost the same but both narratives have tried to substantiate their arguments in their ideological perception.

\section{Breaking the Social Barriers/ Constraints}

The theme of social taboos is also one of the most frequent themes that emerged in the collected data. As stated earlier the \#MeToo movement is unfolding in Pakistan, therefore it has also given vent to talk about social taboos. Earlier topics, like prostitution, women raising voices against injustice, women asking for their rights, etc. which were not allowed to discuss on such social platforms have got public attention and people started talking about such taboos. Most of the tweeps argue that addressing the issues of sexual harassment and domestic violence is the need of the hour. Tweeps believe that the only way to prevent such issues can provide eradication of them and it will also help in bringing the society in its true colors. 


\section{- $\quad$ Prostitution}

While commenting upon the incident of Mohsin Abbas Haider who was accused of domestic violence, MAH17 tweeted that:

"A guy who sleeps with prostitutes is better than a harasser and wife-beater."

It is significant to understand that in Pakistan the concept of prostitution is considered taboo (Chohan, 2011). Now understanding the above-mentioned tweet in the social context of Pakistan, I can argue that Mohsin Abbas Haider's character has been assassinated in terms of social taboos which eventually damage his reputation as a public celebrity. The said tweep suggested that a person who is involved in domestic violence is far more disgusting than a person who sleeps with a prostitute.

\section{- Women Raising Voices for Their Rights}

In Pakistan, there is a part of society that criticizes women for becoming public figures through fighting for causes or becoming victims of violence (Latschan, 2012). Similarly, when someone talks about women's rights they are labeled as bad feminists or hyper feminists thus considering it as a taboo in our society. Another tweep MAH18 UK52 argued that:

"Every time girls try raising their voice for justice, men will cover it up by coming it out emotional saying "what about men's rights? why is no one talking about us? We too suffer and then it comes to an end. No justice for girls. \#MeToo \#Ukhano \#MohsinabbasHaider."

The said tweep argues that in the patriarchal society of Pakistan the movement of women empowerment itself is exposed to certain discrepancies and instead of supporting women, males of the society start comparing their rights and try to devalue the rights of women.

\section{- $\quad$ Calling Out Culture}

It is significant to clarify that in Pakistani culture it is a shameful act to call a guy out i.e. to call a guy immoral or wicked especially in public. For, most people argue that in patriarchal societies man is more respectable and must not be defamed in public. However, social media has reverted the societal schemas and now women publically accuse males thus creating a sense of awareness among the silenced women. One of the tweeps UK53 argues:

"Whenever a lady accused someone of sexual harassment, she was called a liar by the alleged. Why none of them (men) ever admitted it. Aren't they humans and can make mistakes esp in cases (sexual desires) that are tough to control. The accused can't be always wrong! \#Ukhano."

In Pakistan, most of the time when the victims of sexual harassment/domestic violence raise their voices against the prevailing ills of society, they are blamed for their traumas and are trolled and laughed at. However, the above Twitter user argues that being a sensible member of society we must aware that not all voices raised, against sexual harassment and domestic violence, desire fame and the accused must take responsibility for his/her actions because eventually, it not only affects the lives of victims but it gives a huge blow to the \#MeToo movement itself. To favor \#MeToo and encourage the raising voices of women against sexual harassment one of the tweeps MAH19 stated:

"The number of women finding the courage to openly talk about their experiences of abuse and harassment is incredibly powerful. Scoff at the \#MeToo movement all you like, but know this tomorrow it could be your very own daughter. \#MohsinAbbasHaider"

To support women empowerment and the role of \#MeToo is encouraging women to speak their hearts out another tweep MAH20 argued:

"Hats off to FatemaSohail for speaking up against this moron! I hope everyone will stand with her to condemn domestic abuse! Boycott \#MohsinAbbasHaider!"

It is significant to understand that in Eastern society, whenever a female tries to raise her voice she is succumbed and is labeled as a woman who does not take into account the integrity of her family. It can be further argued that raising her voice against any gender discrimination is considered taboo. \#MeToo movement is one of the movements which dismantle the narrative of patriarchy by giving a pathway to social taboos and making such social custom a part of the mainstream narrative. In the same context, another tweep MAH21 argued:

"Take this Mohsin Abbas episode as a reminder that every second woman in Pakistan suffers domestic abuse. These women have been taught this as a cultural norm in 
marriage. They don't have platforms to speak up, neither do they have anyone to support them. \#MohsinAbbasHaider."

In the said tweep we can see how the tweep is lamenting the fact that in Pakistan there are no such platforms provided to them where they can speak their hearts out. Although social media acts as one such platform, however, they are not believed for what they say and argue in their favor.

\section{- $\quad$ An Abusive Marital Relationship}

In Pakistan, a married woman is always pressurized to keep her mouth shut when she suffers in marriage. Sometimes she becomes a part of an abusive marriage relationship but to keep the honor of her marriage intact, she is silenced thus accustoming her to an abusive marriage. In simple words, raising a voice against abusive relationships is taboo. To discourage the silencing of women, one of the tweep MAH22 argued:

"Women in our society are pressured to stay quiet when going through an abusive relationship. For what??? To stay with a lying, abusing monster like \#MohsinAbbasHaider."

The tweep further discouraged the silencing of women over the abusive relationships they are a part of for a long period.

\section{Legal Implications}

The legal implication is a pathway of law and court that helps in providing justice to the victims. It is one of the frequent themes that emerged out of my collected data. For, most of the tweeps believed that law and court are the only way of getting justice respectably. They argued that no one is above law therefore, the accused perpetrator should be taken into the court to provide and explain the truth and in the same way, and the perpetrator will set an example of justice for the rest of the society. Following are the few tweets discussed in this regard:

The first tweet UK40 stated that:

"Hide behind? Ali Zafar took the matter to court and proved his innocence."

This statement suggests that the Twitter user (UK1) has accused those who tried to compare Ukhano's sexual assault case with that of Ali Zafar, accused of sexual harassment by a Pakistani Veteran actress MeeshaShafi, who later took the matter into court and was acquitted of sexual harassment claims. This tweet suggests that Ukhano in one way is accused of sexual harassment and to get his respect back he must take legal action instead of giving vague statements through social media. The consideration of taking legal action will help the public to understand the seriousness of the matter and it will set an example for such future issues as well. In the same context, another tweep UK41 tweeted as:

"I hope the truth wins and justice must be served. Whoever is the victim, the complete investigation must be done, so that no one ever could exploit the law or his/her position. \#Ukhano"

In this tweet, the tweep has emphasized the justice that should be served for the victims. The said tweep strongly supported the process of investigation and argued that such a process should be progressed not only in favor of victims but in the favor of truth as well. If legal actions are taken by the victims of sexual harassment, it will not only help them prove their innocence but it will also help them creating the legacy of rule of law in society. Instead of believing the stories narrated by the others, the victims of sexual harassment and domestic violence should be a part of creating a legal legacy for others. In the same context, one of the tweeps UK43 asserted:

"It's the court decide who's right and who's wrong, prove him wrong and set directions for other victims."

The said tweep further stresses the use of oneself as an agency to create awareness in society by pursuing such issues through the legal lens. Most of the time the accusers of \#MeToo use social media and they intend to manipulate others by posting fake conversations and screenshots. It is due to this reason that the tweeps emphasized the use of legal implications. One of the other tweeps UK44 said:

"No matter who's guilty at the end, the point that needs to be highlighted is there's always a proper procedure for everything i.e. to pursue the case through involving Federal Investigation Agency. Defaming someone socially and using his name to get fame and attention is a cheap stunt. \#Ukhanoexposed \#FIA." 
Although the \#MeToo movement is unfolding in Pakistan and it is yet to produce its impact upon the people, however, several people have taken a stand for their honor and who have exposed the people involved in sexual harassment of others, by taking them to court and by pursuing a legal path of such cases. To appreciate the legal proceedings, one of the tweeps UK45 argued:

"I will just like to appreciate for exposing the network behind people harming the global \#MeToo movement in Pakistan."

The above-mentioned tweet is an appreciation for Ali Zafar who was accused of sexual harassment but he took the matter into court and proved his innocence by defying all the allegations. Similarly, another tweep UK46 focused upon the issue of domestic violence and stated:

"It's very simple his wife should go to court, file charges, and put him in jail we should not be asking for the other side of the story in a domestic battery and abuse case. Let the court decide and no it's not their gharilumamla. It's a criminal offense. \#MohsinAbbasHaider"

The said tweet discouraged a particular clan of social media who were asking for the other side of the story i.e. story of Mohsin Abbas Haider. The tweep argued that the issue of domestic violence should not be internalized rather it should be taken into court to pursue it through proper channels and to pave a path for other victims of domestic violence. Such legal execution of domestic violence cases is the only way to empower women in their lives. Similarly, legal prosecution of such cases gives courage and empowerment to other victims and they muster up the courage to address their issues as well. On one hand, the tweeps asked the victims of sexual harassment to pursue legal actions against the sexual harassers, but on the other hand, certain tweeps have raised the question of law prevailing for the sexual harassers and domestic abusers. As one of the tweeps, MAH9 stated:

"Aren't there any domestic abuse laws in Pakistan? Genuine question.\#MohsinAbbasHaider."

The above tweep asked about the laws of domestic violence and sexual harassment quite ironically. Likewise, another tweep argued that the laws of sexual harassment and domestic violence are quite screwed in our country. The tweep UK47 asserted:

"If anyone says to you let the courts decide, on a sexual harassment, they are automatically canceled because our entire legal system is skewed against victims \#MeToo \#Ukhano."

The above-mentioned analysis, on one hand, displayed a trust in the legal pathway however several tweeps also questioned the authority of law which is full of loopholes. UK47 argues that if the law has had enough power to give punishment to the sexual harassers it would penalize at least a few to set examples.

\section{Fame: A Blame Game for \#MeToo}

On one hand, people troll the victims of sexual harassment and label them as a way of getting fame, on the contrary, several people still believe that media always propagate the agendas of those who are in power or who are financially strong. In such cases, people strongly support the accusers for their courage of speaking up. In the same context a tweep MAH43, UK68 argued:

"We should support those women who are breaking up their silence and not blame

them. We know that the media will give support to their members or those who have

fame and money. MohsinAbbasHaider \#ukhano."

The above tweet is done in the case of Mohsin Abbas Haider. The tweep asserted that women's voices must be heard and encouraged to give them their due credit in society. It also refers to the issue that media play a crucial role in promoting not only false agendas but also by supporting their people i.e. Mohsin Abbas Haider. The said tweep discouraged the role of media in promoting influential people thus manipulating others.

\section{Discussion}

The above-detailed analysis has given a deep insight into the ongoing narrative of \#MeToo in Pakistan in response to patriarchal strands. Both the narratives of patriarchy and women empowerment in Pakistan are governed by self-serving purposes. While deemphasizing the good of the \#MeToo movement, patriarchy argues that the \#MeToo is all about the use of women's cards or victim cards instead of empowering women in society. On the contrary, the \#MeToo narrative argues that through the use of this platform, women have started talking about the societal pseudo-constructed barriers. They have started talking about the abusive marital relationships of which they were a victim for 
decades. Similarly, women have started normalizing the calling out culture which was forbidden in Pakistani culture. They have started calling out men which was, for a long time, forbidden in Pakistan. Similarly, the ongoing debate between patriarchy and the \#MeToo movement has given a way out to the legal procedure in the country. Although patriarchy, again, has deemphasized the narrative of \#MeToo in Pakistan by arguing that social media is not a platform where such delicate issues of domestic violence and sexual harassment but rather such issues should be followed up through a legal procedure. As evident in the analysis section that patriarchy has not only, on one hand, discouraged the use of social media but they have used the law as a threatening tool against victims. Further, patriarchy argues that social media is not a reliable source that does not validate or gives validation to public opinions. It is due to this fact that for patriarchal notions in Pakistan, social media is nothing more than a witch hunt that can swallow the career of anyone with false and fake allegations in no time. In response to this, the \#MeToo narrative argues that in the male-dominated society, justice is served to men most of the time and similarly, the voices of women remain unheard. Social media is a platform through which they can make themselves heard not only by legal clan but by other people as well which helps in elevating the moral support for women.

One of the significant backlashes that the \#MeToo movement has faced in Pakistan is about the movement used as a fame game against men in society. Patriarchy urges that the \#MeToo movement is manipulated by women in society, not only to gain social fame but also financial fame and moral support from the public by manipulating the narrative of the \#MeToo movement. In response to this argument, the proponents of the \#MeToo movement argue that the word 'fame' itself is blame for the movement of women empowerment. \#MeToo narrative further suggests that patriarchal narrative is about promoting inequality and women subjugation in the society. Even though Twitter culture is a hub of international culture but in the conservative, traditionalist, taboostricken Pakistani society, the movement that originated through the international platform is considered a failed movement. One of the significant causes of the failure of the \#MeToo movement is the deep-rooted patriarchy, which is not ready to accept the notion of women empowerment readily. For patriarchal hegemony, patriarchy is the only solution for the social structure of Pakistan. Patriarchy argues that the \#MeToo movement is a western agenda and is used as an ideological tool to manipulate women in Pakistan. Patriarchy, further, asserts that women in Pakistan are using the \#MeToo movement to influence men socially, financially, thus creating a real threat to the narrative of the \#MeToo movement.

\section{Conclusion}

The \#MeToo movement in Pakistan has to struggle a lot to get itself accepted in the deep-rooted patriarchal, traditionalist, and conservative society. In addition to this, by labeling \#MeToo as a movement of attention-seeking, patriarchy is changing the ideological narrative of Pakistan. The literature review of the current study argues that the western narrative of the \#MeToo movement has created awareness in them, as now they are implementing the said narrative in their education policies and have changed the overall power structures. Courts and laws have started acknowledging the issues of sexual harassment and domestic violence. On the contrary, in Pakistan, the narrative of the \#MeToo movement is not contextualized and patriarchy is not ready to accept the ideological agenda of the \#MeToo movement.

\section{Recommendations}

The movement for women empowerment is to be considered in a very broad way and cannot be confined to certain fields. For the success of this movement, continuous efforts are required to change the very mindset of both males and females in society. Seminars, pamphlets, etc. may help in this regard. This would require changes in curricula and a greater understanding of the nature of the phenomenon. PEMRA shall reform its rules and regulations with time to prevent the manipulation of such fragile movements in time. While media campaigns would be helpful a very greater part is to be played by clergy and family traditions.

\section{References}

Ahmadvand, M. (2011).Critical discourse analysis an introduction to major approaches. Jurnal Ilmiah Dinamika Bahasa dan Budaya, 5(1), 82-90.

Apostol, K. (2018, March 14). The power of hashtag activism and how it can help the \#TimesUp movement. Medium. Retrieved from: https://medium.com/women-in-the-industry/the-powerof-hashtag-activism-and-how-it-can-help-the-times-up-movement-e4240a64ebcf. 
Boyle, K. \& Rathnayake, C. (2019). \#HimToo and the networking of misogyny in the age of \#MeToo. Feminist Media Studies. 1-19. doi: 10.1080/14680777.2019.1661868.

Chauhan, K. (2014). Patriarchal Pakistan: Women's representation, access to resources, and institutional practices. Palgrave Macmillan: New York.

Ellis, E. G. (2018, September 27). How \#HimToo became the anti \#MeToo of the Kavanaugh hearings. Wired. Retrieved from: https://www.wired.com/story/brett-kavanaugh-hearingshimtoo-metoo-christine-blasey-ford/.

Evans, A. (2018). \#MeToo: A study on sexual assault as reported in the New York Times. Occam's Razor, 8(3), 11-17. doi: https://cedar.wwu.edu/orwwu/vol8/iss1/3.

Franiuk, R., Seefelt, J.L., Cepress, S.L., \&Vandello, J.A. (2008). Prevalence and effects of rape myths in print journalism: the Kobe Bryant case. Sage Journal, 14(3), 287-309. doi: https://doi.org/10.1177/1077801207313971.

Gash, A., \& Harding, R. (2018). \#MeToo? legal discourse and everyday responses to sexual violence. Laws, 7(2), 1-24. doi: https://doi.org/10.3390/laws7020021.

Kazmi, A. (2018). \#HimToo is the \#alllivesmatter of \#MeToo. The Statesman. Retrieved from: https://www.sbstatesman.com/2018/12/02/himtoo-is-the-alllivesmatter-of-metoo/

Khan, S. K. (2019, April 11). Women are suffering silently in Pakistan - is \#MeToo the answer?. The Guardian. Retrieved from: https://www.theguardian.com/global-development/2019/apr/11/ women-are-suffering-silently-in-Pakistan-is-metoo-the-answer.

Latschan, T. (2012, October 18). A real 'taboo for Pakistani society'. Made for Minds. Retrieved from: https://www.dw.com/en/a-real-taboo-for-pakistani-society/a-16315487.

Mahfooz, S. (2019, January 2). \#MeToo: a failed movement in Pakistan?.TrtWorld. Retrieved from: https://www.trtworld.com/opinion/metoo-a-failed-movement-in-pakistan-23030/.

Mehmood, R. (2018, April 23). Pakistan's long \#MeToo moment. Aljazeera. Retrieved from: https://www.aljazeera.com/indepth/opinion/pakistan-long-metoo-moment180422151525450.html

Ohlheiser, A. (2017, October 17). The woman behind 'Me Too' knew the power of the phrase when she created it -10 years ago. Washington Post. Retrieved from: https://www.washingtonpost. $\mathrm{com} /$ news/the-intersect/wp/2017/10/19/the-woman-behind-me-too-knew-the-power-of-thephrase-when-she-created-it-10-years-ago/.

Rasul, S. (2014). Empowerment of Pakistani women: perceptions and reality. NDU Journal.113-126.

Sayej, N. (2017, December 1). Alyssa Milano on the \#MeToo movement: 'We're not going to stand for it anymore. The Guardian. Retrieved from: https://www.theguardian.com/ culture/2017/dec/01/alyssa-milano-mee-too-sexual-harassment-abuse.

Van Dijk, T. A. (1998). Ideology: A multidisciplinary approach. Thousand Oaks, CA: Sage.

Vardhan, R. (2017). Social media and women empowerment: A sociological analysis. EPRA International Journal of Economic and Business Review, 5(8), 117-121.

Wasif, S. (2018, October 14). 'More cases being reported' as \#MeToo movement picks up in Pakistan. The Express Tribune. Retrieved from: https://tribune.com.pk/story/1825368/1cases-reported-metoo-movement-picks-pakistan/. 